\title{
Improvement of Load Power Factor by Using Capacitor
}

\author{
Ahmad Yani ${ }^{1}$ \\ ${ }^{I}$ (Faculty of Electrical Engineering, STT-Harapan, Medan, Indonesia)
}

\begin{abstract}
Series and parallel capacitors in the power system effect reactive power to improve power factor and voltage because of increasing the system capacity and reducing losses. Reactive power of series capacitor is the same to the current. There are certain unpleasant aspects in the capacitor series. Generally, the cost to install a series capacitor is higher than parallel capacitor. It is caused by complex protection equipment for series capacitor and designing series capacitors for greater power than parallel capacitor to solve the future cost. Installation of capacitors is important to reduce of a system reactive power. Transmission line would be most economical if it is used to send active power where the need of reactive power can be obtained by distribution system in substation level. This will allow user in optimum transmission line, improve operational performance and reduce energy losses. It requires a system and planning carefully to fulfill the need of system reactive power in the same way with active power planning and it is programmed an additional generator capacity.
\end{abstract}

Keywords: Capacitor, parallel, factor, load.

\section{Introduction}

Before discussing about the improvement of power factor by using capacitor, we should recall the general knowledge of Apparent Power, Active Power and Reactive Power. In the electrical system Alternating Current (AC), there are three types of power that are well known, especially to the load impedance (Z) which are: - Apparent Power (S, VA, Volt Ampere), Active Power (P, W, Watt), Reactive Power (Q,VAR, Volt Ampere Reactive).

For the AC power circuit, the voltage and current waveforms are sinusoidal, where the magnitudes of the power at any time are not same. Therefore, the average power is measured in Watts. This power had form active energy per unit in time and can be measured with $\mathrm{Kwh}$ meter and is also a real power or active power (shaft power, actual power) that used by the load to perform a specific task.

While the apparent power expressed in Volt-Ampere units (VA), which is stated the capacity of electrical devices, as shown on the generator and transformer equipment. At some installations, particularly in the plant or industry there are also have specific loads such as electric motors, that is require other type of power, which is reactive power (VAR) to create a magnetic field or it means the reactive power is the power that is used as generation energy of magnetic flux until it caused magnetization and this power is restored to the system due to the effect of electromagnetic induction itself, so that the power is actually the load (demand) in the electrical energy system.

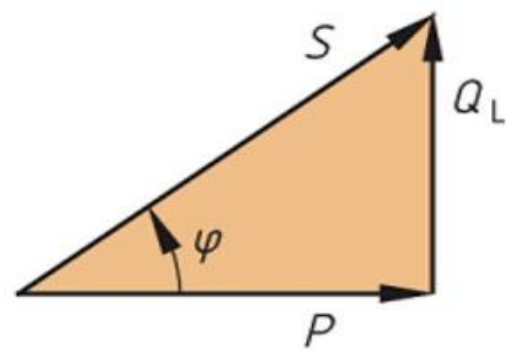

Figure 1: Power Triangle

\subsection{Definition of Power Factor / Work Factor}

\section{Research Methodology}

Power factor or work factor is the comparison between active power (Watt) with apparent power / total power (VA), or cosine angle between active power and apparent power / total power (see Figure 1). The higher reactive power will increase this angle and as the result the power factor will be lower. Power factor is normally lower than or equal to one. Theoretically, if the entire load power that supplied by the electrical company has a unity power factor, so the maximum power transfer is equivalent to the distribution system capacity. Accordingly, with the induced load and if the load factor range from 0.2 to 0.5 , then the capacity of the electricity distribution network becomes depressed. Thus, reactive power (VAR) should be as low as possible 
for the same KW output in order to minimize the total power (VA) requirement. Power factor / work factor is describes the phase angle between active power and apparent power. A lower power factor is disadvantage because it caused higher load current. The improvement of power factor is by using capacitor. Capacitor used to improve the power factor. The power factor can be improved by installing power factor correction capacitors on the electrical distribution system / power installation in factories or industries. The capacitor is act as a reactive power generator and thus it will reduce the amount of reactive power, also apparent power that had been produced by utilities section. An example shows the improvement of power factor with capacitor installation is shown below:

Example 1. A chemical plant to install a $1500 \mathrm{KVA}$ transformer. In the beginning, the plant needs $1160 \mathrm{KVA}$ with a power factor of 0.70 . Percentage of transformer loading is about 78 percent $(1160 / 1500=77.3$ percent $)$. To improve the power factor and to avoid fines by the electricity supplier, the plant added about 410 KVAR in motor load. This improves the power up to 0.89 and reducing the required KVA to $913 \mathrm{KVA}$, which is the total of vector KW and KVAR. Then, $1500 \mathrm{KVA}$ transformer only loads 60 percent of its capacity. So, the plant will be able to increase the load on its transformers in the future.

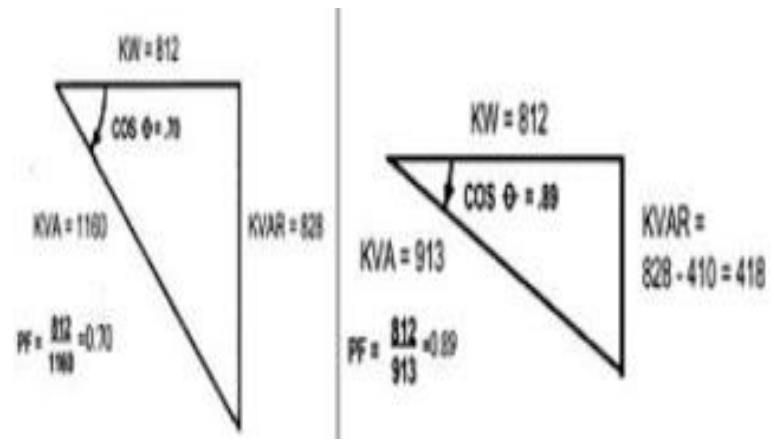

Example 2. A bunch of incandescent lamps with a voltage of $220 \mathrm{~V} / 58 \mathrm{~W}$, combined with the 12 fluorescent lamp $11 \mathrm{~W}$, there are 30 pieces of incandescent and fluorescent lamp. Rated power factor for cos alpha $1=0.5$. Calculate the apparent power of the load and the total of current I1 before compensation, if the needed work factor into cos alpha $2=0.9$ and calculate the magnitude of current $\mathrm{I} 2$ (after compensation).

a) The power total for combined lamp, $\mathrm{PG}=(58 \mathrm{~W} \times 18)+(11 \mathrm{~W} \times 12)=1176 \mathrm{Watt}=1.176 \mathrm{KW}$. Cos phi $1=$ $\mathrm{PG} / \mathrm{S} 1 \ldots . \mathrm{S} 1=\mathrm{PG} / \mathrm{Cos} \mathrm{phi}$

$1=1.176 \mathrm{KW} / 0.5=2.352 \mathrm{KVA}$.

$\mathrm{I} 1=\mathrm{S} 1 / \mathrm{U}=2.352 \mathrm{KVA} / 220 \mathrm{~V}=10.69$ Ampere $(\mathrm{A})$......before compensation.

b) The total power after compensation (Cos phi $=0.9), \mathrm{S} 2=\mathrm{PG} / \mathrm{Cos}$ phi $2=1.176 \mathrm{KW} / 0.9=1.306 \mathrm{KVA}$, so I2 $=\mathrm{S} 2 / \mathrm{U}=1.306 \mathrm{KVA} / 220 \mathrm{~V}=5.94 \mathrm{~A} \ldots .$. after compensation.

\subsection{Advantages of power factor improvement by adding the capacitor.}

The advantages of power factor improvement by adding the capacitor are:

1. For consumers, especially companies or industries:

Required only once investment for the purchase and installation of capacitors and do not have ongoing cost. Reduce the electricity cost for company, because:

Reactive power (KVAR) is no longer supplied by the utility company so that the total demand (KVA) is reduced and the cost of fines being paid when operating at low power factor can be avoided.

\section{For utility electricity supplier:}

Reactive component on network and the total current at the end tip system is reduced. As well as the power loss, I square $\mathrm{R}$ in the system is reduced because the current decreases. The capacity of the electricity distribution network also increases, reduced the need to install additional capacity.

\subsection{Installation of Capacitor Methods.}

\section{Discussions}

The methods to install capacitor can be divided by 3 parts, which are:

\section{Global Compensation}

In this method, the capacitor installed in the main panel (MDP), which the current flow down from this model installation is only in a conductor between MDP panel and transformer. While the passing current after the MDP does not descend thus it cause losses due to heat dissipation in the conductor after the MDP is not affected. Moreover, the power installation with a conductor that sufficiently longs Delta Voltage is still quite large. 


\section{Sectoral Compensation}

With this method, the capacitor consists of several capacitor panels are installed at SDP panel. This method is suitable to be applied in the industry with a larger load capacity installed up to thousand KVA and the distance between first MDP panel and SDP panel are quite far apart.

\section{Individual Compensation}

In this method the capacitor directly installed on each load especially that have highest power. This method is more effective and better in terms of its technical. However, there still has drawback which is must provide space or a special place to put these capacitors, thereby reducing its aesthetic value. Besides, if the machine is installed to hundreds of units, its means the required total cost is higher than the method.

\subsection{The main components that contained in the capacitor panel include:}

\section{Main switch / load break switch}

The main switch is used as a control and isolation equipment if there are maintenance panel. While for cable protection / installation is available on it (from the MDP). Main switch or better known as load break switch is circuit breaker devices and connectivity which is on load where it can be disconnected and connected in an overloaded state, unlike the on-off switch knife models that was only operated when no loaded. To determine the capacity that is used with the calculation at least $25 \%$ larger than the calculation of installed KVAR as example: If the power KVAR had installed $400 \mathrm{KVAR}$ with the current 600 Ampere, then our choices based $600 \mathrm{~A}+25 \%=757$ Ampere so the size used is 800 Ampere.

\section{Capacitor Breaker}

Capacitor breaker is used to protect the cable installation from the breaker to the capacitor bank and also the capacitor itself. The capacity breaker used is 1.5 times nominal current with $\mathrm{Im}=10 \mathrm{xIr}$. To calculate the amount of current, the formula can be used is $\mathrm{In}=\mathrm{Qc} / 3$.VL. For example: The amount of each step from the 10 steps is $20 \mathrm{KVAR}$, then by using above formula obtained the amount of current is 29 Ampere, so the selection of the breaker capacity is $29+50 \%=43 \mathrm{~A}$ or used 40 Ampere. Fuse can also be used besides breaker, the used of fuse is actually better because the respond of the overcurrent and short circuit condition is much better but not efficient in breaking up the operation because this conditions must always have the replacement fuse. The calculation of the fuse usage is also same with the breaker.

\section{Magnetic Contactor}

Magnetic contactor is required as controller devices. Load capacitor has high peak currents, higher than the motor load. For the selection of the magnetic contactor is at least $10 \%$ higher than the nominal current. Selection of magnetic contactor with the higher ampere range would be better so that the life of the magnetic contactor will be longer.

\section{Capacitor Bank}

Capacitor bank is the electrical devices that have capacitive characteristic, which will function as a counterweight to the inductive characteristic. The size of capacitor capacity is from 5 KVAR up to 60 KVAR. From the working voltage of $220 \mathrm{~V}$ to 525 Volt or a capacitor bank is a collection of several capacitors that are connected in parallel to obtain a certain capacitive capacity. The units that often used are KVAR (Kilo Volt Ampere Reactive) even though it contains the amount of capacitance which is in Farad or microfarad. These capacitors have capacitive electrical property (leading). Then, have the property of reduces / eliminates is inductive (lagging).

\section{Reactive Power Regulator}

This device is function to regulate the work of the contactor so that the reactive power that will supply to the network / system can work according to the capacity needed. With the reference to the amount of current and voltage readings on the side of the main breaker, so the reactive power required can be read and the regulator will be set when and how the reactive power needed. This device has a variety steps from 6 steps, 12 steps until 18 steps.

\subsection{Capacitor Installation Connection.}

Connection of delta capacitors (three loads) in the induction motor with slip rings and resistance starter or direct starter, there is no effect if output capacitor does not exceed the power consumption of the motor without load. Conversely if the motor has a delta-star starter, a few problems will be show up, for example, overvoltage due to excitation itself, losses currents and high resonance. Overvoltage for some waves up to two or three times of the voltage limit caused by the excitation itself can occur during the time of transfer from star to delta and the phase line cut-off before neutral line disconnected. When the transference from the star to delta 
occurs at the times of phase and neutral lines is open together, the overvoltage does not occurs, but higher losses current may happens when the motor is turned on again. This is because the voltage on the capacitor remains the same during the termination time but when the line voltage reconnected at the different phase, it cause the protection current in danger.

At the time of transfer from star to delta, the connection point of neutral is open before the phase line made a series resonance between capacitor and motor winding. The amount of it is until like a short circuit and suddenly the current increase very high that is suitable with the overvoltage at the capacitor and motor winding. These difficulties can be avoided if used a six-pole capacitor that connected in a single phase. The difference of connection for low voltage capacitor with six pole connection, series resonance cannot be happening because the motor winding and capacitor are always connected in parallel. The risk of excitation itself will not exist again. Current protection no longer increases, because the capacitors discharge its load through the motor winding when disconnected from the phase line. Therefore, the usage of six pole capacitor is suitable for stardelta motor. It has been observed that the usage of three pole capacitor has a tendency that contact starter line has closed before contact starter open, so the capacitor connected in series with the phase stator windings. Hence, this has led to increase in resonance and overvoltage, causing damages to the motor and capacitor. Below are some examples of capacitors connection installation methods.

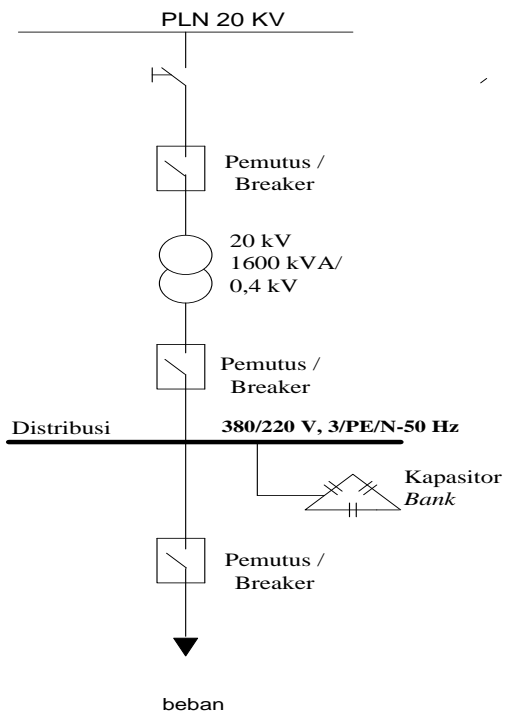

Figure 1 Installation of Capacitors Bank Global Compensation System

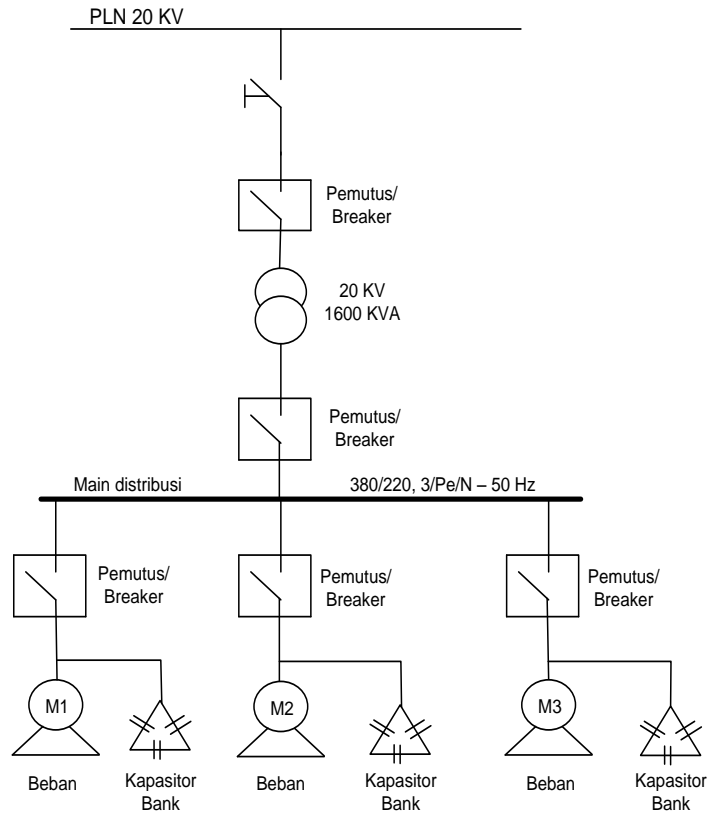

Figure 2Individual Compensation 


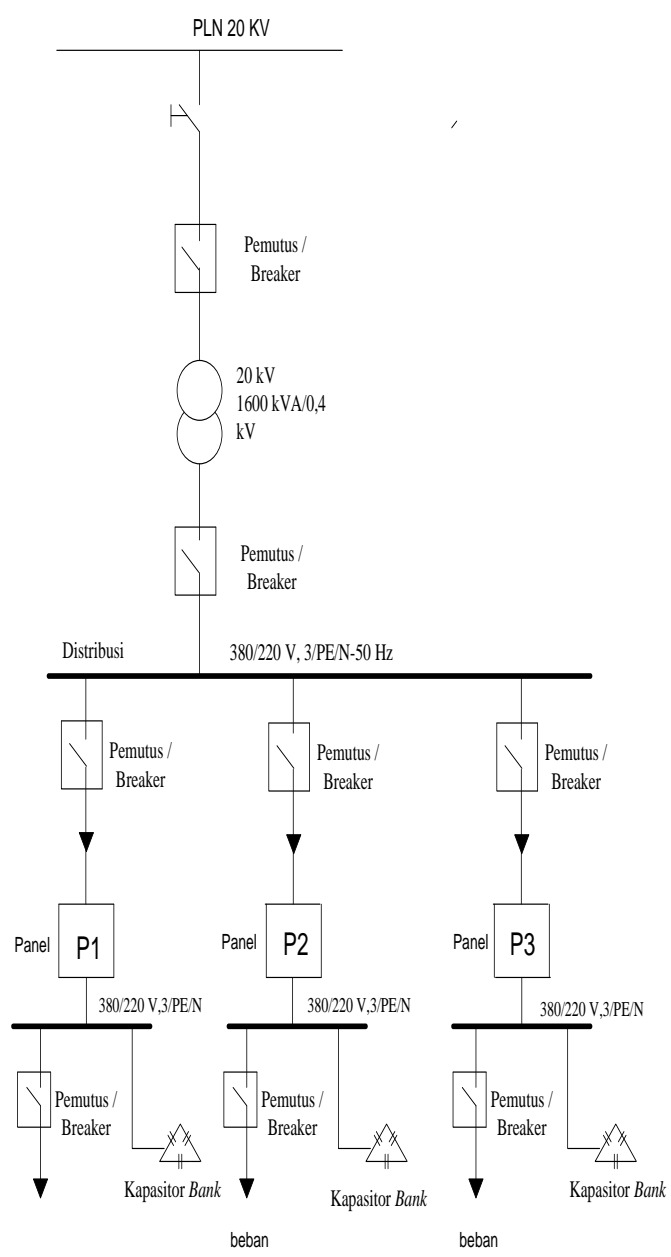

Figure 3installation of Capacitors Bank Sectoral Compensation System

\section{Conclusion And Recommendation}

By installing capacitors in the electrical power circuit, there are some advantages:

1. The losses of KW / KVAR are very small, which is from 0.0025 up to 0.005 .

2. Simple installation / installation and maintenance, does not required a foundation because of light and no rotating parts likes synchronous motor.

3. The other benefit for consumers is reduces the KVA needed, power loss and voltage is stable.

\section{References}

[1]. Abdul Kadir, Penghantar Teknik Tenaga Listrik, 1980, Jakarta LP3ES

[2]. AS. Pabla, Sistem Distribusi Daya Listrik, Erlangga, 1994

[3]. Ir. Muslimin Marpaung, Teknik Tenaga Listrik, 1979, Bandung Armico.

[4]. Zuhal, Dasar Tenaga Listrik, 1979,ITB 